\title{
Executive summary of the CAEP 2014 Academic Symposium: How to make research succeed in your department
}

\author{
Ian G. Stiell, MD, MSc*; Jennifer D. Artz, $\mathrm{PhD}^{\dagger}$; Jeffrey Perry, MD, MSc*; \\ Christian Vaillancourt, MD, MSc*; Lisa Calder, MD, MSc*
}

\section{ABSTRACT}

The vision of the recently created Canadian Association of Emergency Physicians (CAEP) Academic Section is to promote high-quality emergency patient care by conducting worldleading education and research in emergency medicine. The Academic Section plans to achieve this goal by enhancing academic emergency medicine primarily at Canadian medical schools and teaching hospitals. It seeks to foster and develop education, research, and academic leadership amongst Canadian emergency physicians, residents, and students. In this light, the Academic Section began in 2013 to hold the annual Academic Symposia to highlight best practices and recommendations for the three core domains of governance and leadership, education scholarship, and research. Each year, members of three panels are asked to review the literature, survey and interview experts, achieve consensus, and present their recommendations at the Symposium (2013, Education Scholarship; 2014, Research; and 2015, Governance and Funding).

Research is essential to medical advancement. As a relatively young specialty, emergency medicine is rapidly evolving to adapt to new diagnostic tools, the challenges of crowding in emergency departments, and the growing needs of emergency patients. There is significant variability in the infrastructure, support, and productivity of emergency medicine research programs across Canada. All Canadians benefit from an investigation of the means to improve research infrastructure, training programs, and funding opportunities. Such an analysis is essential to identify areas for improvement, which will support the expansion of emergency medicine research. To this end, physician-scientist leaders were gathered from across Canada to develop pragmatic recommendations on the improvement of emergency medicine research through a comprehensive analysis of current best practices, systematic literature reviews, stakeholder surveys, and expert interviews.

\section{RÉSUMÉ}

La section des affaires universitaires de l'ACMU, mise sur pied il y a quelques années seulement, a pour vision de promouvoir la prestation de soins de qualité aux patients dans les services des urgences en faisant de la recherche et en donnant de la formation de classe mondiale en médecine d'urgence. La section cherche à atteindre ce but en mettant en valeur le champ de la médecine d'urgence en milieu universitaire, principalement dans les écoles de médecine et dans les hôpitaux d'enseignement. Elle cherche aussi à stimuler et à développer la formation, la recherche et le pouvoir d'influence en milieu universitaire parmi les urgentologues ainsi que les résidents et les étudiants en médecine d'urgence. C'est donc dans cette optique que la section a commencé à tenir, en 2013, des symposiums annuels sur les affaires universitaires, afin de mettre en évidence les pratiques exemplaires et les meilleures recommandations dans les trois domaines de base, soit la gouvernance et le pouvoir d'influence, les bourses d'études et la recherche. Chaque année, des membres des trois groupes d'experts examinent la documentation, mènent des enquêtes parmi les experts et ont des entrevues avec ceux-ci, dégagent un consensus et présentent leurs recommandations à l'occasion du colloque (2013: les bourses d'études; 2014: la recherche; 2015: la gouvernance et le financement).

La recherche est essentielle au progrès de la médecine. Étant une spécialité relativement jeune, la médecine d'urgence évolue rapidement pour s'adapter aux nouveaux outils de diagnostic, faire face à l'encombrement des services des urgences et répondre aux besoins sans cesse croissants des patients traités dans ces services. Toutefois, il existe des différences importantes entre les programmes de recherche en médecine d'urgence au Canada en ce qui concerne I'infrastructure, le soutien et la productivité. Pourtant, l'ensemble de la population canadienne profite de la recherche de moyens visant à améliorer l'infrastructure relative à la recherche, les programmes de formation en la matière et les possibilités de financement. II est primordial de procéder à ce genre d'analyse afin de cerner les zones d'amélioration; en effet, c'est sur les résultats obtenus que s'appuiera l'expansion de la recherche en médecine d'urgence. Aussi les principaux cliniciens-chercheurs de partout au Canada ont-ils élaboré des recommandations pragmatiques sur l'amélioration de la recherche en médecine

From the *Department of Emergency Medicine, Ottawa Hospital Research Institute, University of Ottawa, Ottawa, ON; and +Canadian Association of Emergency Physicians (CAEP), Ottawa, ON.

Correspondence to: Dr. Ian G. Stiell, Ottawa Hospital, Civic Campus, Clinical Epidemiology Unit, F6, 1053 Carling Avenue, Ottawa, ON, Canada K1Y 4E9; Email: istiell@ohri.ca 
d'urgence en procédant à une analyse globale des pratiques exemplaires en cours, à des revues systématiques de la documentation, à des enquêtes parmi les différents intervenants et à des entrevues avec des experts.
Keywords: academics, career researchers, emergency medicine, funding, research, residents

\section{CAEP 2014 ACADEMIC SYMPOSIUM}

The 2014 Academic Symposium was entitled, "How to Make Research Succeed in Your Department." The current landscape and best practices to improve Canadian emergency medicine research at academic units (whether an official department, division, section, or unspecified) were identified by convening three panels to develop practical recommendations on how to make academic research succeed. Each panel was chaired by an experienced Canadian emergency medicine researcher and included at least six other emergency medicine physician-scientists from across Canada. The panels were responsible for thoroughly researching their topics, which included 1) promoting excellence in Canadian emergency medicine resident research, 2) how to develop and train career researchers in emergency medicine, and 3) how to fund emergency medicine research programs. Each panel used mixed methods and presented their recommendations at the CAEP 2014 Academic Symposium on May 31, 2014, in Ottawa, Ontario. Dynamic discussions and suggestions provided at the symposium (which had 80 attendees, including physician-scientists, educators, administrators, clinicians, and residents) augmented and refined the recommendations, which are summarized herein and will be presented in detail in the next three CFEM issues. ${ }^{1,2,3}$

\section{Promoting Excellence in Canadian Emergency Medicine Resident Research}

This panel (chaired by Dr. Lisa Calder) identified sparse literature describing the current state of Canadian emergency medicine resident research. As a foundational step, they proposed a concise definition for a scholarly project that allowed for diverse types of academic inquiries, such as empiric research, educational projects, and quality improvement. Second, they specifically defined the three levels of research competence: critical appraiser of research, research contributor, and research producer. Finally, they delineated the unique circumstances within the Canadian dual-college training system, which includes their different philosophies toward research training and their training capacities. These distinctions were carefully considered by the panel as part of the recommendations.

From data gathered through a systematic review of the literature and survey of all of the program directors from both colleges, the panel iteratively developed recommendations by group consensus. In addition to vetting at the CAEP 2014 Academic Symposium, these recommendations were also distributed to stakeholders for feedback, including the Specialty Committee of the Royal College of Physicians and Surgeons of Canada (RCPSC), the Emergency Medicine Interest Focused Practice Committee of the College of Family Physicians of Canada (CFPC), and the CAEP Resident Section.

The recommendations focused on addressing Canada-wide variability, including specifics directed at both colleges to clarify expectations and to academic units to provide supports conducive to fostering excellence in resident research (Box 1).

\section{How to Develop and Train Career Researchers in Emergency Medicine}

This panel (chaired by Dr. Jeffrey Perry) addressed the best practices for training and developing emergency medicine career researchers by identifying the enablers and barriers. They conducted a systematic review and survey of all Canadian emergency medicine researchers. The expert research panelists also studied the Society for Academic Emergency Medicine (SAEM) research fellowship program. Recommendations based on this methodology were presented at the CAEP 2014 Academic Symposium and refined from attendee feedback.

A survey of physicians who were self-defined as a clinical researcher (i.e., physicians who spend a significant portion of their career conducting research) was conducted. Respondents felt that salary support, research training, mentorship, and infrastructure positively impact the success of a clinical research career. Review of the SAEM research fellowship identified specific core competencies for researchers, as well as mandatory manuscript preparation and submission of a 
Box 1. Summary of recommendations: promoting excellence in Canadian emergency medicine resident research

\subsection{Recommendations to the two national colleges}

1.1.1 Specific clarification is recommended around the goals and exit competencies for emergency medicine residents from both colleges, so they are clearly aligned with the college training objectives. The desired competency outcome (i.e., critical appraiser, research contributor, and/or research producer) and an explicit definition for "scholarly project" should be declared.

1.1.2. For the RCPSC emergency medicine programs, a range of research opportunities should be available to meet all competency outcomes, including a stream for advanced research training (e.g., MSc or PhD).

1.1.3. For the CFPC emergency medicine programs, a clear path for those interested in further research training should be defined.

1.1.4. The RCPSC should address the variability across its programs and consider the advantages of a structured research training curriculum offered early to provide residents more research opportunities.

1.1.5. Given the two family medicine years plus one emergency medicine year in CFPC emergency medicine training, the CFPC should identify specific research training elements necessary to supplement the family medicine research training curriculum.

\subsection{Recommendations for local programs}

1.2.1 RCPSC programs should develop a research training curriculum for their residents matched to desired competency outcomes.

1.2.2 All residency programs should assess individual resident research projects as well as evaluate their resident research programs as a whole.

1.2.3. All programs should consider using a resident research coordinator to facilitate research ethics board application, project management, publication, and program evaluations.

1.2.4. Resident research programs should link to existing infrastructure (in other programs or medical departments) to assist residents with scholarly project design and statistical analysis.

1.2.5 All programs should dedicate research funding support toward resident research.

1.2.6 All programs should consider matching residents with research mentors (who can provide methodological and pragmatic support). This can also occur outside of the program and/or the institution.

1.2.7. All residency programs should encourage their residents to broadly disseminate project results (whether by traditional publication or other peer-reviewed venues), including manuscript preparation by RCPSC residents and abstract presentation by all residents (at least locally, but ideally nationally).

1.2.8. Resident research abstracts and manuscript publications should be tracked as a metric for the evaluation of academic productivity.

large grant proposal for peer review as integral to a successful research training program.

The panel's work culminated into the recommendation of a structured research training program, which would consist of two phases: formal fellowship/graduate training (2 years) and research consolidation (1 to 3 years) (Box 2).

\section{How to Fund Emergency Medicine Research Programs}

This panel (chaired by Dr. Christian Vaillancourt) outlined research funding strategies, including tactics to fund research projects, salaries, infrastructure, and stipends. By interviewing other research leaders using a standardized questionnaire of open-ended questions, local research funding strategies from across Canada were characterized. Examples of commonly used funding opportunities were also compiled at the provincial, national, and international levels. By iterative consensus, practical recommendations about improving research funding at the academic level were developed and refined following discussions at the CAEP 2014 Academic Symposium.

They identified four local research funding models that included 1) an investigator-dependent model, 2) practice plans, 3) generous benefactors, and 
Box 2. Summary of recommendations: how to develop and train career researchers in emergency medicine

\subsection{Required elements of a CAEP Academic Section endorsed training programs}

2.1.1. Training should consist of two phases: Phase I: Research Fellowship/Graduate Training (2 years) and Phase II: Research Consolidation (1-3 years).

2.1.2. Phase I should comprise both an advanced research degree (e.g., MSc Epidemiology) and practical mentorship covering the 15 domains of clinical research (see 2.3).

2.1.3. Phase II should focus on intense mentoring to consolidate the 15 domains of clinical research and develop expertise in research outputs (e.g., abstracts, manuscripts, and grants).

2.1.4. Training centres are encouraged to formalize links with other centres to cover areas of expertise that are not well established in their own centres.

2.1.5. Trainees in both Phase I and Phase II require protected time away from clinical, educational, and administrative duties.

2.1.6. A research salary/stipend is essential during both phases of this training.

2.1.7. Work space, including appropriate infrastructure (i.e., computer, Internet access, reference software, statistical software, administrative support), needs to be provided to both Phase I and Phase II trainees.

2.2. Process to become a CAEP Academic Section endorsed training program

2.2.1. Ensure that a plan exists on how to provide training in all 15 domains of clinical research.

2.2.2. Apply to the CAEP Academic Section to receive endorsement for research training of candidates for Phase I, Phase II, or both.

2.2.3. Provide updates every 5 years to the CAEP Academic Section on the number of trainees per phase and an updated plan on how training is provided in the 15 domains of clinical research.

\subsection{Domains of clinical research for Phase I and Phase II training}

2.3.1. Identification of research focus within emergency medicine

2.3.2. Hypothesis generation

2.3.3. Research design

2.3.4. Data collection methods

2.3.5. Data monitoring and interim data analysis

2.3.6. Data analysis

2.3.7. Presentation of research

2.3.8. Manuscript preparation, submission, and revision

2.3.9. Knowledge translation

2.3.10. Project management

2.3.11. Ethical aspects of medical research

2.3.12. Regulatory requirements

2.3.13. Informatics

2.3.14. Teaching skills

2.3.15. Career development

2.4. Additional requirements for Phase II training

2.4.1. Submit and present two or more scientific abstracts per year.

2.4.2. Submit at least two full manuscripts as first author per year.

2.4.3. Obtain at least one grant from a provincial or national peer-review organization, including preparation, submission, and revision.

2.4.4. Consolidate 15 domains of clinical research Phase I.

4) a mixed-funding model. Expert-led discussions of the advantages and challenges of these models resulted in recommendations specific to individual researchers and organizations, including those for research contributors and producers, local academic leaders, and national emergency medicine bodies (Box 3). 


\section{CONCLUSION}

The CAEP Academic Section Executive supports these recommendations to improve emergency medicine research in Canada. Working with stakeholders, including the colleges, program directors, emergency medicine physician-scientists, academic leaders, and CAEP as a whole, the CAEP Academic Section will assist local emergency medicine units to learn and improve from these recommendations. One improvement process recently endorsed by the CAEP Board of Directors will be the offer of expert consultations to each university emergency medicine unit for research programs, as well as for the other academic domains of education scholarship and governance/funding. We hope that the 2014 research recommendations will

Box 3. Summary of recommendations: how to fund emergency medicine research programs

\subsection{Recommendations for research contributors and producers, including learners, faculty members without research training, young investigators, and mid-career and senior investigators}

3.1.1. Researchers should obtain research training

3.1.2. Learners should collaborate with and be mentored by trained investigators and/or methodologists in all grant applications.

3.1.3 If such mentorship is not available within the emergency medicine academic community, efforts should be made to collaborate with investigators from other disciplines, including nonclinician methodologists.

3.1.4. Faculty members without research training can start as co-supervisor/collaborator on other learner/ faculty member small projects, seek support from an institutional method centre, or collaborate with investigators from other disciplines.

3.1.5 Young investigators should be mentored by mid-career/senior investigators, be provided with protected research time in order to increase productivity, and give careful consideration to the timing of their first academic appointment in order to remain eligible for new investigator salary awards.

3.1.6 Mid-career/senior investigators should develop research programs leading to large grant opportunities and collaboration with research networks.

3.1.7 Mid-career/senior investigators should include funding for trainees, including MSc/PhD students and post-doctoral fellows when applying for all operating grants.

\subsection{Recommendations for local academic leaders}

3.2.1. Academic centres should foster a culture of research among their trainees and faculty and reward both participation and excellence.

3.2.2. Efforts should be made to train, recruit, and retain investigators interested and dedicated to emergency medicine.

3.2.3. Local/institutional funding for research activities should be encouraged at all levels of training.

3.2.4. Academic centres should strive to implement a mixed-funding model or, at the least, institute a practice plan in order to support research activities.

3.2.5. Departments and research groups should consider "funding-contingent" positions, where the outside funding used to support a university full-time research position comes from the potential clinician scientist (i.e., clinical income), and this is leveraged by matching dollars or supplements from the faculty or academic department.

\subsection{Recommendations for national organizations}

3.3.1. CAEP should maintain and expand its current offering of small grants, and consider larger grants programs such as training grants.

3.3.2. CAEP researchers should advocate for emergency medicine representation by qualified investigators among national funding agencies such as the Canadian Institute for Health Research (CIHR).

3.3.3. CAEP and emergency medicine researchers should advocate for an emergency-medicine-specific funding stream such as, for example, a ClHR emergency medicine institute. 
help the Canadian emergency medicine community create high-quality evidence to improve care of our patients.

Acknowledgements: All of the recommendations from the CAEP 2015 Academic Symposium are published in the above summary and the articles from each panel. ${ }^{1,2,3}$ The authors of the CAEP 2014 Academic Symposium would like to thank all of the panelists: Riyad Abu-Laban, Barbara Blackie, Bijon Das, Marcel Émond, Jason Frank, Rob Green, Corinne Hohl, Judd Hollander, Brian Holroyd, Grant Innes, Natalie Le Sage, Shelley McLeod, Laurie Morrison, Brian Rowe, Carolyn Snider, Venkatesh Thiruganasambandamoorthy, and Rob Woods, as well as Sedigheh Shaeri, who assisted with the career researcher literature review.

\section{REFERENCES}

1. Perry et al. CAEP 2014 Academic Symposium: "How to make research succeed in your emergency department: How to develop and train career researchers in emergency medicine." C7EM 2015;17(3):334-43.

2. Vaillancourt et al. CAEP 2014 Academic Symposium: "How to make research succeed in your emergency department: How to fund your research program." CFEM 2015; forthcoming.

3. Calder et al. CAEP 2014 Academic Symposium: "How to make research succeed in your emergency department: Promoting excellence in Canadian emergency medicine resident research." CFEM 2015; forthcoming. 